\title{
Sugar tags and tumorigenesis
}

\author{
Usha Nagarajan $^{1 *}$, Shanmugasundaram Pakkiriswami ${ }^{2}$ and Agieshkumar B. Pillai ${ }^{3}$ \\ ${ }^{1}$ School of Chemical and Biotechnology, SASTRA University, Thanjavur, India, ${ }^{2}$ Department of Biology, University of Western \\ Ontario, London, ON, Canada, ${ }^{3}$ Central Inter-Disciplinary Research Facility, Sri Balaji Vidyapeeth, Puducherry, India
}

Keywords: HSPG, glycosyltransferases, tumorigenesis, glycosaminoglycans, Drosophila melanogaster

\section{OPEN ACCESS}

Edited by:

Leonardo Freire-de-Lima,

Federal University of Rio de Janeiro,

Reviewed by:

Héctor Herranz,

University of Copenhagen, Denmark

Luciana Boffoni Gentile,

Federal University of Rio de Janeiro,

Brazil

${ }^{*}$ Correspondence:

Usha Nagarajan

ushibiotech@gmail.com

Specialty section:

This article was submitted to

Molecular and Cellular Oncology,

a section of the journal

Frontiers in Cell and Developmental

Biology

Received: 17 September 2015

Accepted: 19 October 2015

Published: 04 November 2015

Citation:

Nagarajan U, Pakkiriswami S and Pillai $A B$ (2015) Sugar tags and tumorigenesis.

Front. Cell Dev. Biol. 3:69.

doi: 10.3389/fcell.2015.00069
The fact that the cell surface and extracellular matrix (ECM) component heparin sulfate proteoglycans (HSPGs) bind to various growth factor molecules and distribute them to targeted cell locations is known for many years (Spring et al., 1994; Nakato et al., 1995; Baeg et al., 2001; Nybakken and Perrimon, 2002; Voigt et al., 2002; Fujise et al., 2003; Johnson et al., 2004; Steigemann et al., 2004). However only during the last few years the significance of producing functional proteoglycans that regulate the signaling activities are gaining importance (Sarrazin et al., 2011). Proteoglycans are widespread from bacteria to humans with diverse expression patterns. Structural and functional features of proteoglycans possess immense ability to either promote or inhibit tumorigenesis. Members of HSPG family (glypicans, syndecans, and perlecans) function as co-receptors for several growth-related signaling pathways such as Wg, Hh, Dpp to mediate various processes like proliferation, differentiation, morphogenesis, cell-adhesion, and cell migration (Reviewed in Lin, 2004; Yan and Lin, 2009). Studies in Drosophila have shown that glypicans like Dally (Belenkaya et al., 2004; Han et al., 2004; Vuilleumier et al., 2010; Ferreira and Milán, 2015) and Dally-like (Dlp) (Gallet et al., 2008; Szuperák et al., 2011) facilitate movement of signaling molecules to regulate tissue growth. Recent research updates demonstrate the novel role of HSPGs in regulating additional signaling pathways like JAK/STAT (Zhang et al., 2013); PI3K and TOR (Ferreira and Milán, 2015) and also in cross-talk between signaling pathways (Wg and Dpp) to mediate tumorigenesis and metastasis (Freire-de-Lima, 2014; Herranz et al., 2014; Häuselmann and Borsig, 2014). These reports underscore the importance of studying the role of functional proteoglycans.

Interest among researchers has increased in the last few years as a result of findings in humans that list the growing number of hereditary diseases and tumors caused by mutations of the genes encoding enzymes involved in the biosynthesis of HSPGs. For example, human patients with Simpson-Golabi-Behmel syndrome (SGBS), caused by mutations in a glypican member, GPC3, suffer from tissue overgrowth that eventually develops into neuroblastomas (Pilia et al., 1996). Similarly children aged between 10 and 15 years lacking the enzymes required for synthesis of these proteoglycans, display kidney tumors called Wilm's tumors leading to eventual death (Pilia et al., 1996; Capurro et al., 2008). Few studies have also showed that distortion in the expression levels of yet another glypican family GPC1, leads to cervical and pancreatic cancers (Kleeff et al., 1998; Chen and Lander, 2001; Filmus et al., 2008). In similar lines, updates on secreted glypican, perlecans functioning as oncogenes suggested that tumorigenesis and metastasis are initiated due to the defective and non-functional proteoglycans. Defective proteoglycans are suggested to dysregulate the cell cycle and proliferation events of the neighboring host cells, thereby allowing tumor cells to invade and spread throughout the organism (Fuster and Esko, 2005; Herranz et al., 2014). However, the mechanism by which the changes in glypican function in tumorigenesis and tumor metastasis is still not clear. It is suggested that how quickly a tumor changes its properties totally depends on the tumor composition and environment.

Abbreviations: ECM, extracellular matrix; HSPG, heparansulfate proteoglycan; HS, heparansulfate; GAG, glucosaminoglycans; CS, chondroitinsulfate;HNK-1, human natural killer-1; PI3K, phosphatidylinositol 3-kinase; TOR, target of rapamycin; JAK/STAT, janus kinase/signal transducer and activator of transcription. 
Tumor formation and progression involves a set of unique changes in inter- and intracellular signaling. Recent reports illustrate that transformed host cells possess highly modified and non-functional proteoglycans on their cell surface (Christianson et al., 2013). These proteoglycans have been identified to promote and mediate critical patho-physiological events during various steps of tumor progression. However, only handful of factors involved in the proteoglycans synthesis are known and many more remains to be identified. In addition to the core proteins, Heparin Sulfate (HS), and Chondroitin-Sulfate (CS) chains of glycosaminoglycans (GAGs) are shown to possess specific functions. The di/tetrasaccharides linked to the core protein enable the proteoglycans to bind various signaling molecules. In functional proteoglycans, GAG-chains bind to the signaling molecules and distribute them at appropriate places while in the nonfunctional proteoglycans, GAG-chains either cannot bind to the signaling molecules or release them effectively. Problems in signaling modulation thereby leads to developmental defects and tumorigenesis. With the given importance of proteoglycans, it is highly intriguing to understand the processes underlying GAG synthesis.

Several studies have demonstrated the importance of HS chains comprising long unbranched repeats of disaccharide units of glucosamine and uronic acid. HS biosynthesis is asystematic three step process of chain initiation, elongation, and modifications. Proteoglycans biosynthesis is initiated at the GAG attachment sites on the core protein. Following this, several glycosyltransferases and modification enzymes elongate and modify the GAG chains (Esko and Selleck, 2002). Some of the enzymes known in HS GAG elongation and modifications are sugarless (sgl), sulfateless (sfl), and few Drosophila EXT proteins, including Tout-velu (Ttv), Sister of ttv (Sotv), and Brother of ttv (Botv) (Lin, 2004). It has been demonstrated that signaling molecules like Wg (Han and Lin, 2005), Hh (Bornemann et al., 2004; Han et al., 2004; Takei et al., 2004), and dpp (Belenkaya et al., 2004; Bornemann et al., 2004) fail to traffic in cells which are defective for components of HS GAG synthesis (encoded by $s f$, sotv, and botv genes). Recent study showing aberrant JAK/STAT signaling due to loss of $s f$ suggested that HS chains on glypicans are indispensable for their signaling activity (Zhang et al., 2013).

Inspite of these understanding on proteoglycans, the fundamental question of how these glypicans are synthesized has not been addressed in detail. For instance, the molecules that participate in the process of chain initiation are not studied. Physiological and pharmacological evidences have been provided in other model system like rat to demonstrate the role of chain initiation step of Chondroitin-Sulfate (CS) in cell communication and development by inhibiting in proteoglycans synthesis (Margolis et al., 1991).Direct evidences from totuvelu (ttv or EXT1 in vertebrates), enzymes involved in HS-chain elongation and modifications, that function as tumor suppressors and implicated in bone overgrowth of humans (Ahn et al., 1995; Stickens et al., 1996) indicate that HS-derived GAG levels are dramatically reduced due to non-functional proteoglycans (Toyoda et al., 2000).

Chain initiation process of proteoglycans will be affected either due to modifications in the core proteins to which the initial GAG molecules are attached or mutations in the factors that transfer di/tri-saccharides to the core proteins (Baeg and Perrimon, 2000). Therefore, generation and investigation of mutants for chain initiation factors would help to explore the role of functional proteoglycans. Enzymes involved in HS chain initiation and processing are highly tissue and developmental stage specific in their function. These specific modifications enable the HSPGs in signal reception and ligand distribution. Hence mutations in biosynthetic process of glypicans would generate non-functional HSPGs, which in turn, lead to catastrophic developmental consequences (Figure 1).

Till date none of the studies have characterized the role of HS GAG chain initiation-factors related to tumorigenesis. Some of the chain initiation factors like GlcAT-S, a glycosyltransferase is required for the synthesis of conserved glycosaminoglycanprotein linkage region of proteoglycans. The carbohydrate epitope Human Natural Killer 1 (HNK-1) attached by glycosyltransferase is present on several cell adhesion molecules that mediate cell-cell interactions. The HNK-1 epitope composed of specific trisaccharide (- $\left.\mathrm{HSO}_{3}-3 \mathrm{GlcA} \beta 1-3 \mathrm{Gal} \beta 1-4 \mathrm{GlcNAc}-\right)$ structure is sequentially synthesized by glycouronosyl transferases (like GlcAT-S or GlcAT-P) or sulphotransferase (HNK-1ST). Glucuronyl transferase like GlcAT-S is one of the major enzymes involved in biosynthesis of proteoglycans and glycoproteins. It also modifies the Human Natural Killer 1 (HNK-1) epitope bearing ECM proteins (Pandey et al., 2011; Yamamoto-Hino et al., 2015). These chain-initiating factors are highly significant as they contribute to the rate limiting step-of proteoglycans synthesis. Therefore, any disruption to initiation process will dramatically affect the downstream reactions of chain elongation and modification generating non-functional and defective proteoglycans. Once these enzymes are identified, model organisms with defective proteoglycans can be created to address its role in maintaining tissue integrity.

To obtain a better understanding, it is now highly critical to investigate the mutant phenotypes associated with chain initiation enzymes and their interaction with core proteins. In line with this, glypican 3 (GPC-3) mutant mice show drastic developmental disorders, characterized by pre- and post-natal overgrowth. In addition, the study also illustrated Glypican 3 modulation is associated with development of endothelial, colon and ovarian cancers in adults (Filmus, 2001). Mutant animals for these glycosyltransferases tend to develop mild growthrelated phenotypes like variation in organ sizes and overgrowth during the early stages of development (Filmus, 2001; Pandey et al., 2011; Yamamoto-Hino et al., 2015). During late stages of development these animals eventually display severe phenotypes due to the production and accumulation of defective and nonfunctional proteoglycans. Repertoire of mutants needs to be generated to precisely explore the various roles of functional proteoglycans and understand physiological conditions required for the growth factor signaling molecules binding to them at different affinities. In addition, issues related to functional redundancy among these HSPGs can be analyzed either by testing the phenotypes of double mutants or by expressing a specific HSPG core protein in the mutant background of the enzymes involved in chain initiation. Mechanisms operate in Drosophila to 

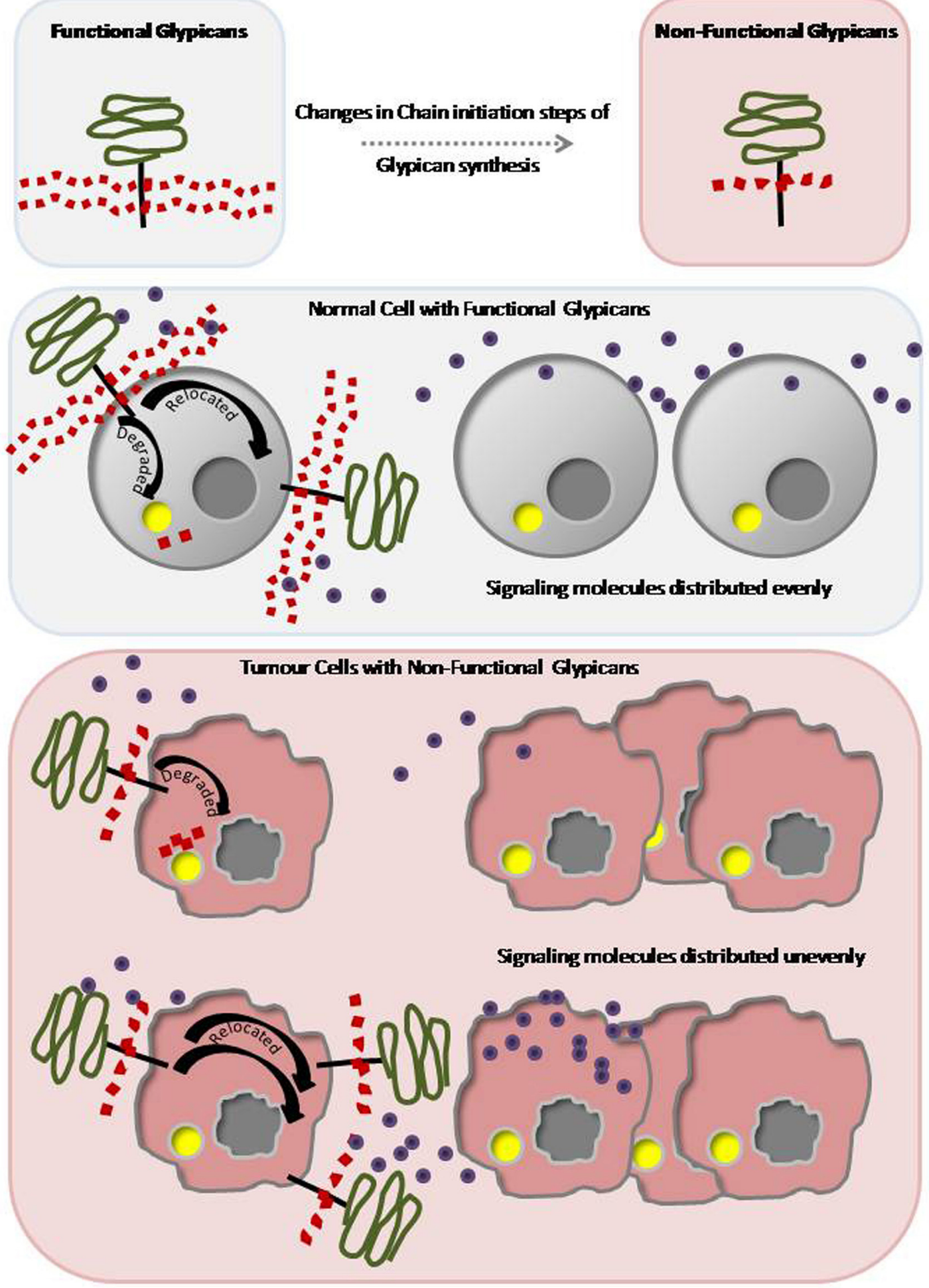

FIGURE 1 | Defective and Non-functional proteoglycans lead to developmental disorders and tumorigenesis. Schematic representation of a functional proteoglycan with long GAG branches and a non-functional proteoglycan with short GAG branches. Any change in the chain-initiation steps of glypican synthesis leads to formation of non-functional proteoglycans. In a normal cell, functional proteoglycans with GAG branches bind to the signaling molecules. The proteoglycans are either relocated or recycled to evenly distribute the signaling molecules. In tumorous cell, defective and non-functional GAG branches cannot either bind to the signaling molecules or release them appropriately. Non-functional proteoglycans are either recycled continuously or mislocated leading to changes in distribution of signaling molecules thereby producing developmental disorders and tumorigenesis. 
produce functional proteoglycans are similar to the one observed in vertebrates and humans. The knowledge gained in fly model may provide a further understanding into the molecular basis of adult onset diseases and tumorigenesis in humans.

\section{AUTHOR CONTRIBUTIONS}

UN, SP, and AP designed experiments; UN performed experiments analyzed the data. UN wrote the manuscript. $\mathrm{UN}, \mathrm{SP}$, and AP revised the manuscript.

\section{REFERENCES}

Ahn, J., Lüdecke, H. J., Lindow, S., Horton, W. A., Lee, B., Wagner, M. J., et al. (1995). Cloning of the putative tumour suppressor gene for hereditary multiple exostoses (EXT1). Nat. Genet. 11, 137-143. doi: 10.1038/ng1095-137

Baeg, G. H., Lin, X., Khare, N., Baumgartner, S., and Perrimon, N. (2001). Heparan sulfate proteoglycans are critical for the organization of the extracellular distribution of wingless. Development 128, 87-94. doi: 10.1042/bst029 a010c

Baeg, G. H., and Perrimon, N. (2000). Functional binding of secreted molecules to heparan sulfate proteoglycans in drosophila. Curr. Opin. Cell Biol. 12, 575-580. doi: 10.1016/S0955-0674(00)00134-4

Belenkaya, T. Y., Han, C., Yan, D., Opoka, R. J., Khodoun, M., Liu, H., et al. (2004). Drosophila Dpp morphogen movement is independent of dynaminmediated endocytosis but regulated by the glypican members of heparan sulfate proteoglycans. Cell 119, 231-244. doi: 10.1016/j.cell.2004.09.031

Bornemann, D. J., Duncan, J. E., Staatz, W., Selleck, S., and Warrior, R. (2004). Abrogation of heparan sulfate synthesis in drosophila disrupts the wingless, hedgehog and decapentaplegic signaling pathways. Development 131, 1927-1938. doi: 10.1242/dev.01061

Capurro, M. I., Xu, P., Shi, W., Li, F., Jia, A., and Filmus, J. (2008). Glypican-3 inhibits hedgehog signaling during development by competing with patched for hedgehog binding. Dev. Cell 14, 700-711. doi: 10.1016/j.devcel.2008. 03.006

Chen, R. L., and Lander, A. D. (2001). Mechanisms underlying preferential assembly of heparan sulfate on glypican-1. J. Biol. Chem. 276, 7507-7517. doi: 10.1074/jbc.M008283200

Christianson, H. C., Svensson, K. J., van Kuppevelt, T. H., Li, J.-P., and Belting, M. (2013). Cancer cell exosomes depend on cell-surface heparan sulfate proteoglycans for their internalization and functional activity. Proc. Natl. Acad. Sci. U.S.A. 110, 17380-17385. doi: 10.1073/pnas.1304266110

Esko, J. D., and Selleck, S. B. (2002). Order out of chaos: assembly of ligand binding sites in heparan sulfate. Annu. Rev. Biochem. 71, 435-471. doi: 10.1146/annurev.biochem.71.110601.135458

Ferreira, A., and Milán, M. (2015). Dally proteoglycan mediates the autonomous and nonautonomous effects on tissue growth caused by activation of the PI3K and TOR pathways. PLoS Biol. 13:e1002239. doi: 10.1371/journal.pbio. 1002239

Filmus, J. (2001). Glypicans in growth control and cancer. Glycobiology 11, 19R23R. doi: 10.1093/glycob/11.3.19R

Filmus, J., Capurro, M., and Rast, J. (2008). Glypicans. Genome Biol. 9:224. doi: 10.1186/gb-2008-9-5-224

Freire-de-Lima, L. (2014). Sweet and sour: the impact of differential glycosylation in cancer cells undergoing epithelial-mesenchymal transition. Front. Oncol. 4:59. doi: 10.3389/fonc.2014.00059

Fujise, M., Takeo, S., Kamimura, K., Matsuo, T., Aigaki, T., Izumi, S., et al. (2003). Dally regulates Dpp morphogen gradient formation in the drosophila Wing. Development 130, 1515-1522. doi: 10.1242/dev.00379

Fuster, M. M., and Esko, J. D. (2005). The sweet and sour of cancer: glycans as novel therapeutic targets. Nat. Rev. Cancer 5, 526-542. doi: 10.1038/nrc1649

Gallet, A., Staccini-Lavenant, L., and Thérond, P. P. (2008). Cellular Trafficking of the glypican dally-like is required for full-strength hedgehog signaling

\section{ACKNOWLEDGMENTS}

We thank Dr. Matt Gibson from Stowers Institute for Medical Research, Kansas City, MO USA for his support. We also thank Drs. Swaminathan Sethuraman, Vijayalakshmi Mahadevan, and Umamaheswari Krishnan of SASTRA University, India for support and providing laboratory facilities. We also thank Dr. Devendra Singh for helpful discussion and critical comments on this draft. Startup grant from Science and Engineering Research Board (SERB), Department of Science and Technology, Government of India (YSS/2014/000896) to UN.

and wingless transcytosis. Dev. Cell 14, 712-725. doi: 10.1016/j.devcel.2008. 03.001

Han, C., Belenkaya, T. Y., Wang, B., and Lin, X. (2004). Drosophila glypicans control the cell-to-cell movement of hedgehog by a dynamin-independent process. Development 131, 601-611. doi: 10.1242/dev.00958

Han, C., and Lin, X. (2005). Shifted from Wnt to hedgehog signaling pathways. Mol. Cell 17, 321-322. doi: 10.1016/j.molcel.2005.01.009

Häuselmann, I., and Borsig, L. (2014). Altered tumor-cell glycosylation promotes metastasis. Front. Oncol. 4:28. doi: 10.3389/fonc.2014.00028

Herranz, H., Weng, R., and Cohen, S. M. (2014). Crosstalk between epithelial and mesenchymal tissues in tumorigenesis and imaginal disc development. Curr. Biol. 24, 1476-1484. doi: 10.1016/j.cub.2014.05.043

Johnson, K. G., Ghose, A., Epstein, E., Lincecum, J., O’Connor, M. B., and Van Vactor, D. (2004). Axonal heparan sulfate proteoglycans regulate the distribution and efficiency of the repellent slit during midline axon guidance. Curr. Biol. 14, 499-504. doi: 10.1016/j.cub.2004. 02.005

Kleeff, J., Ishiwata, T., Kumbasar, A., Friess, H., Büchler, M. W., Lander, A. D., et al. (1998). The cell-surface heparan sulfate proteoglycan glypican-1 regulates growth factor action in pancreatic carcinoma cells and is overexpressed in human pancreatic cancer. J. Clin. Invest. 102, 1662-1673. doi: 10.1172/ JCI4105

Lin, X. (2004). Functions of heparan sulfate proteoglycans in cell signaling during Development. Development 131, 6009-6021. doi: 10.1242/dev.01522

Margolis, R. K., Goossen, B., Tekotte, H., Hilgenberg, L., and Margolis, R. U. (1991). Effects of beta-xylosides on proteoglycan biosynthesis and morphology of PC12 pheochromocytoma cells and primary cultures of rat cerebellum. J. Cell. Sci. 99(Pt 2), 237-46.

Nakato, H., Futch, T. A., and Selleck, S. B. (1995). The division abnormally delayed (dally) gene: a putative integral membrane proteoglycan required for cell division patterning during postembryonic development of the nervous system in drosophila. Development 121,3687-3702.

Nybakken, K., and Perrimon, N. (2002). Heparan sulfate proteoglycan modulation of developmental signaling in drosophila. Biochim. Biophys. Acta 1573, 280-291. doi: 10.1016/S0304-4165(02)00395-1

Pandey, R., Blanco, J., and Udolph, G. (2011). The glucuronyltransferase GlcAT$\mathrm{P}$ is required for stretch growth of peripheral nerves in drosophila. PLoS ONE 6:e28106. doi: 10.1371/journal.pone.0028106

Pilia, G., Hughes-Benzie, R. M., MacKenzie, A., Baybayan, P., Chen, E. Y., Huber, R., et al. (1996). Mutations in GPC3, a glypican gene, cause the simpson-golabibehmel overgrowth syndrome. Nat. Genet. 12, 241-247. doi: 10.1038/ng03 96-241

Sarrazin, S., Lamanna, W. C., and Esko, J. D. (2011). Heparan sulfate proteoglycans. Cold Spring Harb. Perspect. Biol. 3:a004952. doi: 10.1101/cshperspect.a004952

Spring, J., Paine-Saunders, S. E., Hynes, R. O., and Bernfield, M. (1994). Drosophila syndecan: conservation of a cell-surface heparan sulfate proteoglycan. Proc. Natl Acad. Sci. U.S.A. 91, 3334-3338.

Steigemann, P., Molitor, A., Fellert, S., Jäckle, H., and Vorbrüggen, G. (2004). Heparan sulfate proteoglycan syndecan promotes axonal and myotube guidance by Slit/robo signaling.Curr. Biol. 14, 225-230. doi: 10.1016/j.cub.2004.01.006 
Stickens, D., Clines, G., Burbee, D., Ramos, P., Thomas, S., Hogue, D., et al. (1996). The EXT2 multiple exostoses gene defines a family of putative tumour suppressor genes. Nat. Genet 14, 25-32. doi: 10.1038/ng0996-25

Szuperák, M., Salah, S., Meyer, E. J., Nagarajan, U., Ikmi, A., and Gibson, M. C. (2011). Feedback regulation of drosophila BMP signaling by the novel extracellular protein larval translucida. Development 138, 715-724. doi: 10.1242/dev.059477

Takei, Y., Ozawa, Y., Sato, M., Watanabe, A., and Tabata, T. (2004). Three drosophila EXT genes shape morphogen gradients through synthesis of heparan sulfate proteoglycans. Development 131, 73-82. doi: 10.1242/dev.00913

Toyoda, H., Kinoshita-Toyoda, A., and Selleck, S. B. (2000). Structural analysis of glycosaminoglycans in drosophila and caenorhabditis elegans and demonstration that tout-velu, a drosophila gene related to EXT tumor suppressors, affects heparan sulfate in vivo. J. Biol. Chem. 275, 2269-2275. doi: 10.1074/jbc.275.4.2269

Voigt, A., Pflanz, R., Schäfer, U., and Jäckle, H. (2002). Perlecan participates in proliferation activation of quiescent drosophila neuroblasts. Dev. Dyn. 224, 403-412. doi: 10.1002/dvdy. 10120

Vuilleumier, R., Springhorn, A., Patterson, L., Koidl, S., Hammerschmidt, M., Affolter, M., et al. (2010). Control of Dpp morphogen signalling by a secreted feedback regulator. Nat. Cell Biol. 12, 611-617. doi: 10.1038/ncb2064
Yamamoto-Hino, M., Yoshida, H., Ichimiya, T., Sakamura, S., Maeda, M., Kimura, Y., et al. (2015). Phenotype-based clustering of glycosylation-related genes by RNAi-mediated gene silencing. Genes Cells 20, 521-542. doi: 10.1111/gtc. 12246

Yan, D., and Lin, X. (2009). Shaping morphogen gradients by proteoglycans.Cold Spring Harb. Perspect. Biol. 1:a002493. doi: 10.1101/cshperspect.a002493

Zhang, Y., You, J., Ren, W., and Lin, X. (2013). Drosophila glypicans dally and dally-like are essential regulators for JAK/STAT signaling and unpaired distribution in eye development. Dev. Biol. 375, 23-32. doi: 10.1016/j.ydbio.2012.12.019

Conflict of Interest Statement: The authors declare that the research was conducted in the absence of any commercial or financial relationships that could be construed as a potential conflict of interest.

Copyright $\odot 2015$ Nagarajan, Pakkiriswami and Pillai. This is an open-access article distributed under the terms of the Creative Commons Attribution License (CC BY). The use, distribution or reproduction in other forums is permitted, provided the original author(s) or licensor are credited and that the original publication in this journal is cited, in accordance with accepted academic practice. No use, distribution or reproduction is permitted which does not comply with these terms. 